\title{
O HOMEM E SUAS FRONTEIRAS: UMA LEITURA CRÍTICA DO USO CONTEMPORÂNEO DA CATEGORIA DE PERVERSÃO
}

Eduardo Leal Cunha

Eduardo Leal Cunha Psicanalista.

Doutor em Saúde Coletiva (IMS/

Uerj). Professor do Programa de Pós-graduação em Psicologia Social e do Departamento de Psicologia da UFS. Membro do Espaço Brasileiro de Estudos Psicanalíticos.
RESUMO: Retoma-se uma questão central à discussão nosográfica em psicanálise e que se refere ao estatuto da perversão e à sobreposição entre psicopatologia e código moral. Partindo de leituras contemporâneas que privilegiam o uso da categoria de perversão na crítica da contemporaneidade, procuramos destacar o valor moral de tal uso, bem como suas implicações teóricas e éticas. Em seguida, procuramos mostrar como tal uso se vincula ainda à demarcação de limites para o humano, indicando a necessidade de repensar a categoria de perversão, tendo como referência tal discussão sobre o que define a humanidade.

Palavras-chave: Perversão, moral, desmentido (Verleugnung), humanidade, psicanálise.

ABSTRACT: Mankind and its borders: a critical reading on the contemporary use of the category of perversion. This paper resumes a central issue in the psychoanalytical nosographic discussion concerning the status of perversion and the overlap between psychopathology and moral code. Starting with contemporary readings that emphasize the use of the category of perversion in the critique of the contemporary world, we try to stress the moral value of such use, as well as its theoretical and ethical implications. Then, we show how such use is linked to the demarcation of boundaries for the human being, indicating the need to rethink the category of perversion, having such discussion on what defines humanity as a reference.

Keywords: Perversion, morality, disavowal (Verleugnung), humanity, psychoanalysis.

DOI - http://dx.doi.org/10.1590/S1516-14982016000100006 
$\mathrm{N}$ osso interesse volta-se para a problemática perversa em função da proliferação de leituras críticas da sociedade contemporânea que apontam para o reconhecimento da generalização ou mesmo banalização da perversão como forma privilegiada de subjetivação.

Mais do que isso, é importante perceber que, como apontam Mello Neto \& Schmitt (2011), a partir de um levantamento em publicações científicas de psicologia indexadas a bases de dados internacionais, grande parte dos textos que se voltam para tal articulação entre perversão e contemporaneidade é de autoria de brasileiros.

Nestes textos, pode-se constatar o uso da categoria de perversão como instrumento de denúncia das mazelas do mundo contemporâneo, como a violência e o consumismo excessivo, o que é apontado ainda por Cecarelli (2011), que nos alerta para o fato de que o adjetivo perverso é usado muitas vezes para identificar comportamentos que, na clínica ou fora dela, nos causam estranheza ou angústia.

O termo perversão pode aparecer para dar conta de casos mais específicos, referidos aos novos modos de laço social no capitalismo neoliberal, como nas relações de trabalho (GONZAGA JR., 2008); enquanto elemento central na explicação das formas atuais de drogadição (GURFINKEL, 2007); no entendimento das estratégias da publicidade de bens de consumo (KEHL, 2008); ou, ainda, tendo como foco o campo da sexualidade, enquanto principal arma no enfrentamento entre autores do campo psicanalítico e os adeptos da chamada teoria queer (FLORES, 2010).

Nosso argumento inicial é de que tal uso pode indicar não a banalização de experiências, atos ou modos de funcionamento subjetivo que deveriam ser considerados perversos, mas do próprio conceito, que corre assim o risco de perder seu rigor e valor enquanto ferramenta simbólica de elaboração, numa perspectiva estritamente psicanalítica, dos impasses da clínica e da cultura.

Trata-se então de criticar certa visão consensual da perversão, a qual, como no funcionamento do mito contemporâneo e burguês descrito por Roland Barthes (1985), valores morais são naturalizados, tomados como verdade evidente por si, fazendo com que, no caso específico da perversão, uma categoria que deveria servir à compreensão clínica de experiências subjetivas singulares, acabe, ao contrário, por encobrir a singularidade de determinadas experiências, ao mesmo tempo em que as desqualifica.

Nosso ponto de chegada, por sua vez, será uma tentativa de encontrar função e lugar para a categoria de perversão numa psicanálise voltada para formas contemporâneas do mal-estar, a partir da delimitação do tipo de impasse subjetivo e ético diante do qual fomos levados historicamente a recorrer ao termo perversão, tanto na sua forma substantiva quanto em seu uso como adjetivo. Com esse objetivo, procuramos reconhecer a dimensão moral do uso da noção de 
perversão, sem, contudo, nos submetermos a tal dimensão, à codificação moral ou à axiologia que dela pode derivar, nem, por outro lado, desmentir seu vínculo com os contextos sócio-históricos nos quais tal uso se efetiva.

Assim, procuraremos interrogar a base moral do uso atual da categoria de perversão, sobretudo na medida em que ela se apresenta preponderantemente em sua forma adjetiva e então propor algumas considerações em torno do lugar e valor que a mesma pode merecer no pensamento psicanalítico, na clínica e, em especial, na crítica psicanalítica da cultura e dos modos de organização social. Sobretudo na medida em que é um conceito no qual se articulam de modo radical: a reflexão clínica — o enfoque no sujeito singular e em seus modos de sofrimento - , e a reflexão ética, com a interrogação dos vínculos possíveis entre modos de sofrer, processos de subjetivação e formas de viver junto.

Para tanto, privilegiaremos duas obras recentes nas quais se destaca como elemento comum o reconhecimento de uma generalização da perversão no mundo contemporâneo, seja com a produção de uma perversão comum (perversion ordinaire), enquanto forma hegemônica de subjetivação (LEBRUN, 2008), seja através da constatação de que nos dirigimos para a construção de uma sociedade perversa (ROUDINESCO, 2008). Tal escolha se deve não apenas ao fato de tais obras se constituírem em análises mais aprofundadas do tema, mas também pelo seu impacto e citação recorrente em textos e discussões atuais sobre o tema no Brasil, e, ainda, por estarem vinculadas à matriz lacaniana e às discussões iniciais sobre o tema na França.

Os dois textos partem, ainda, de perspectivas diferentes e tal diferenciação nos permite abordar aqueles que nos parecem os dois principais pontos problemáticos no uso que o pensamento psicanalítico contemporâneo faz da ideia de perversão: de um lado, a produção de uma continuidade entre as mais diversas práticas qualificadas de perversas, em diferentes contextos históricos e sob o primado de códigos morais distintos, sendo tal continuidade apoiada fundamentalmente no vínculo entre perversão e maldade, com base no que o ato perverso é percebido como a materialização de um gozo do mal (ROUDINESCO, 2008); de outro lado, a vinculação entre a ideia de perversão e uma leitura psicanalítica da cultura que se apoia na afirmação da existência de invariantes antropológicos que condicionariam não apenas a constituição do sujeito, mas a própria entrada do homem na ordem da cultura (LEBRUN, 2008), sendo tal entrada o marco limite que separa o homem do animal e estabelece as fronteiras da humanidade.

Explorando tais pontos críticos, nos dirigiremos a uma interrogação do uso psicanalítico da perversão de modo a questionar seu aprisionamento em certo vício de origem, a saber, a tentativa de estabelecer uma justificação científica para determinado regime de codificação moral, a qual, sobretudo, a partir do século XIX, tornou necessária a separação radical entre práticas normais e anormais no 
campo sexual, produzindo assim formas de regulação da sexualidade que, ao menos em nível ideal, seriam axiologicamente neutras (LANTERI-LAURA, 1994).

É nossa intenção ainda indicar de modo breve que o deslocamento da perversão do campo da sexualidade para o campo dos fenômenos socioculturais (PEIXOTO JR., 1999) não liberou o uso da categoria de perversão desta sua marca de origem, mas, ao contrário, a aproximou do antigo sentido de perversidade e manteve seu uso - em especial na forma da atribuição do adjetivo perverso(a) - dependente do código moral.

Com isso, esperamos não a supressão do uso do termo, mas sua devida contextualização histórica, de modo que ao enunciarmos o diagnóstico de perversão o façamos tendo consciência das implicações éticas e dos limites teóricos e clínicos de tal diagnóstico. Ou seja, admitimos o valor da noção de perversão, mas acreditamos que o mesmo depende do reconhecimento da sua dimensão histórica e de seu comprometimento com o código moral, estando em tal reconhecimento a possibilidade de seu uso efetivo tanto na clínica psicanalítica quanto em uma crítica da cultura que se apoie na psicanálise.

Por fim, apontaremos para a hipótese de que, considerando tal vinculação com a moralidade e o contexto histórico, o fio que une as diversas formas da experiência subjetivas designadas em diferentes contextos como perversas não estaria em um modo particular de economia ou estruturação psíquica, mas na colocação em risco do reconhecimento possível do outro enquanto ser humano, condição mínima para o estabelecimento dos laços identificatórios que, segundo Freud, operam a manutenção dos laços sociais (FREUD, 1921/2011). Desse modo, o recurso à perversão se daria precisamente nos momentos em que percebemos ameaçada nossa compreensão do humano e dos seus limites, ou seja, momentos em que nossa ideia ou ideal de homem não parece dar conta do tipo de experiência subjetiva com a qual nos defrontamos na clínica ou fora dela.

\section{UMA CONTINUIDADE PERVERSA}

O elemento central da obra de Elizabeth Roudinesco é a retomada do que é apresentado, desde o próprio subtítulo, como uma história dos perversos. Trata-se, portanto, de com os olhos postos no contemporâneo e no que poderia ser descrito como formas novas ou prevalentes da perversão na atualidade, encontrar um fio comum que garanta unidade a essa história e, além disso, mostre que a perversão não é uma excrescência ou excepcionalidade, mas algo que habita o sujeito, a "parte obscura de nós mesmos" (ROUDINESCO, 2008). A produção de tal unidade é o primeiro alvo de nossa crítica.

Note-se, logo de início, que o objeto não é a perversão, mas os perversos, e que temos aí, de forma paradoxal, contraposta a uma multiplicidade de expe- 
riências, a unicidade da forma subjetiva que sustentaria tais práticas, o que, aliás, aparece de modo mais evidente na fórmula subjetividade pervertida (ROUDINESCO, 2008, p.9 e 205).

Temos, então, uma leitura que aponta para a produção contemporânea de uma sociedade perversa, apoiada no reconhecimento de uma unidade da perversão, a qual se ancora, por sua vez, em uma estrutura subjetiva vinculada ao "gozo do mal” (ROUDINESCO, 2008, p.11). Este é na verdade o grande elemento unificador de personagens tão díspares quanto o Marquês de Sade e Osama Bin Laden. ${ }^{1}$

Encontramos aí um sinal claro daquilo que Peixoto Jr. (1999) descreve como deslocamento da perversão do campo sexual para o domínio do laço social, o qual marca uma série de leituras psicanalíticas das perversões, em especial a partir da experiência do holocausto e dos enigmas colocados por tal experiência. Sustentam tal deslocamento, por um lado, o relaxamento dos vínculos necessários entre perversão e desvio sexual, apoiado, por sua vez, na noção lacaniana de estrutura perversa, sobretudo com base na leitura de Piera Aulagnier-Spairani (2003) e na concepção de um modelo tripartite da personalidade (DOR, 1987); e, por outro lado, as transformações naquilo que se pode chamar de semiologia perversa, antes pensada como pertencendo basicamente ao campo estrito da sexualidade, das práticas eróticas, e que, ao longo do século XX, incorporou aos poucos uma série de práticas vinculadas à crueldade e à destruição do outro, como, por exemplo, a tortura.

Desse modo, se, por um lado, certas práticas sexuais ficaram mais ou menos livres do adjetivo perverso, como é o caso sobretudo do homoerotismo, por outro lado, tornaram-se foco privilegiado do diagnóstico da perversão aquelas experiências vinculadas à crueldade e à produção de dano ao outro. ${ }^{2}$

Falta, no entanto, considerar os diversos efeitos de tal deslocamento, sobretudo na medida em que se produz com ele uma aproximação cada vez maior entre a perversão e a perversidade, posto que o resultado do ato perverso seria necessariamente “desqualificar ou a ferir o outro" (FERRAZ, 2000, p.7), de modo que se cristaliza o laço entre perversão e maldade, ao mesmo tempo em que se

\footnotetext{
${ }^{1}$ É importante registrar a incrível recorrência da expressão "gozo do mal” ao longo do texto de Roudinesco (2008): p.10n; 11; 35; 44; 58; 75; 99; 101; 162; 163.

2 É importante perceber que tal deslocamento nunca se dá de modo completo ou definitivo. Assim, por um lado, o transexualismo ainda aparece como experiência perversa, na qual, aliás, se combinam subversão da identidade sexual e dano ou crueldade, ainda que esta tenha como alvo o próprio sujeito, que se mutilaria em busca do seu gozo transgressivo e em nome do desafio à lei da diferença sexual; por outro lado, ainda que o desejo por indivíduos do mesmo gênero não seja mais considerada explicitamente uma perversão, se tomamos um autor como Ferraz (2000), por exemplo, percebemos que em todos os exemplos clínicos de perversão apresentados, os pacientes são homens homossexuais, como se a perversão não habitasse mais o homoerotismo, mas uma vizinhança bastante próxima, ou seja, como se este trouxesse ainda em si, no mínimo, a potencialidade perversa.
} 
desconsidera que é difícil pensar a ideia de maldade fora do registro moral ou sem referência ao Bem, o que nos remete por sua vez ao problema dos ideais e dos seus determinantes sócio-históricos, ou seja, à dificuldade de se pensar no Mal em si, absoluto ou fundamental, prévio ao juízo dos homens e das culturas em que estes vivem.

A vinculação entre gozo e maldade não é, contudo, o único elemento distintivo do perverso, já que tal gozo habitaria em cada um de nós, ao menos como potência. Os perversos são ainda identificados pelos efeitos que produzem, sendo o principal deles a colocação em risco da genealogia ${ }^{3}$ e, assim, do próprio gênero humano. Aí reside sua maldade, aquela que põe em risco o humano, seja rebaixando o homem a objeto ou animal, seja buscando a superação da humanidade em direção ao divino.

“A perversão é sempre, queiramos ou não, sinônimo de perversidade. E, sejam quais forem seus aspectos, ela aponta sempre, como antigamente, mas por meio de novas metamorfoses, para uma espécie de negativo da liberdade: aniquilamento, desumanização, ódio, destruição, domínio, crueldade, gozo. (...) Mas a perversão é também criatividade, superação de si, grandeza. Nesse sentido, pode ser entendida como o acesso à mais elevada das liberdades, uma vez que autoriza aquele que a encarna a ser simultaneamente carrasco e vítima, senhor e escravo, bárbaro e civilizado. O fascínio exercido sobre nós pela perversão deve-se precisamente a que ela pode ser ora sublime, ora abjeta. Sublime ao se manifestar nos rebeldes de caráter prometeico, que se negam a submeter à lei dos homens, ao preço de sua própria exclusão; abjeta ao se tornar, como nas ditaduras mais ferozes, a expressão soberana de uma fria destruição de todo laço genealógico.” (ROUDINESCO, 2008, p.11)

Ou seja, mesmo considerando a possibilidade de uma face sublime da perversão, muitas vezes ligadas à dimensão religiosa ou mítica dessa ultrapassagem das fronteiras que delimitariam a humanidade, mantém-se em Roudinesco o vínculo entre perversão e perversidade, ou seja, entre o desvio e a maldade, identificado por Lanteri-Laura (1994) como marca fundamental e ponto crítico da apropriação médica das perversões.

Será, no entanto, todo desvio, toda transgressão à lei moral, por exemplo, da ordem do mal, portanto, perverso? Seriam todos os atos qualificados como perversos fiéis à etimologia do termo, ou seja, desvios, adulterações, transgressões? Ou, ainda, seria o respeito à norma jurídica sempre necessariamente a melhor

\footnotetext{
${ }^{3}$ Em sentido próximo, Lebrun (2008) vai afirmar que a constituição de uma coletividade perversa coloca em risco as duas grandes hierarquias fundamentais à genealogia do sujeito: a diferença sexual e a diferença de gerações.
} 
conduta ética e desejável? E o que dizer quando é a norma que produz a morte ou a destituição subjetiva do outro?

Assim, a referência à transgressão no quadro de uma reflexão sobre a concepção psicanalítica de perversão pode nos mostrar que esta última se apresenta como tentativa de circunscrição dos desvios à norma moral e legal no interior de uma racionalidade de base médica, tomada a partir de então como ferramenta auxiliar do direito.

Segundo Birman (2008), no entanto, se seguirmos a trilha de Foucault em torno de uma genealogia da ideia de transgressão em seu vínculo com a modernidade e com a tarefa de produção de uma normatividade própria apoiada nas ciências humanas, em particular a partir do modelo da própria clínica médica, tal aproximação deve nos fazer, ao contrário, exatamente problematizar a sobreposição entre norma jurídica e lei simbólica, já que seria esta última, fundada na interdição do incesto, aquela que seria ultrapassada na transgressão perversa que a psicanálise, sobretudo depois de Lacan, toma como objeto privilegiado e ponto de ancoragem de uma estruturação subjetiva particular.

O que não significa que a própria formulação do reconhecimento da lei simbólica como condição necessária à produção desejante e à constituição do sujeito deva ser tomada desde o início como verdade inegociável ou absoluta. O que se articula à discussão que se segue, sobre a proximidade existente entre a discussão sobre a perversão e a reflexão sobre o que define o humano em psicanálise, inclusive na medida em que isso pode remeter à identificação, na psicanálise, de um humanismo, isto é, de uma concepção do homem genérico, de uma demarcação da sua identidade essencial bem como das suas condições de possibilidade (SOUZA, 1993).

Voltando às proposições de Roudinesco e ao fio de continuidade que se estabelece entre as múltiplas formas de transgressão, pode-se perceber, por outro lado, que a perversão aparece como contraponto à liberdade, o que de fato eleva esta ao nível de ideal e nos coloca ao menos duas perguntas fundamentais: será a liberdade um ideal universal? Terá liberdade um único significado?

Delineiam-se desse modo, ao longo da exposição de Roudinesco, determinadas linhas a circunscrever o "povo dos perversos" (ROUDINESCO, 2008, p.89). Ao lado da contraposição à liberdade, aparecem não só “aniquilamento, desumanização, ódio, destruição, domínio, crueldade, gozo” e a “destruição de todo laço genealógico”, mas também a ideia de animalidade e de metamorfose, categorias próximas do imaginário da perversão no século XIX, momento decisivo de sua apropriação pela medicina: a monstruosidade e a degeneração (LANTERI-LAURA, 1994). Desse modo, acaba por se tecer uma malha que aprisiona em uma mesma categoria — referida a um modo comum de funcionamento psíquico, de estruturação subjetiva - experiências que nos 
parecem tão diversas quanto: "zoofilia, pedofilia, terrorismo, transexualidade" (ROUDINESCO, 2008, p.10).

Tais linhas de continuidade, como esperamos ter destacado o suficiente, recorrem de modo preferencial a uma terminologia de caráter moral, e, para ser mais preciso, negativamente moral e, com isso, perverso e perversa tornam-se adjetivos que expressam antes de tudo o juízo de quem o enuncia, fazendo com que discurso psicanalítico contemporâneo sobre a transgressão, apoiado nessa concepção de perversão como gozo do mal, converta-se sempre em discurso de poder, engendrando o erro e a culpa daquele que o recebe (BARTHES, 1996).

Ao se produzir uma longa história da perversão, como pretendeu Roudinesco, negligencia-se a ruptura radical que se produz pela apropriação médica do crime e do desvio e o fato de que é preciso localizar com precisão o momento histórico em que a perversão se constitui como objeto do conhecimento médico e jurídico, agrupando uma série de atos e práticas até então dispersas e sem aproximação aparente e, ao mesmo tempo, produzindo uma separação entre o perverso - ou o "povo dos perversos", como quer Roudinesco - e o restante da humanidade, o que só é possível fazer na medida em que o olhar, do médico ou do juiz, se desloca do ato para o indivíduo que o pratica e em seguida lhe confere uma identidade capaz de, num mesmo movimento, inscrevê-lo em um círculo de pertencimento e localizá-lo em um território de exceção em relação, primeiro à norma, depois, com a assimilação entre perverso e monstruoso, em relação à própria humanidade.

Além desta dificuldade basal, consideramos importante destacar dois outros efeitos produzidos ao se estabelecer uma continuidade entre práticas distintas - e muitas vezes bem distantes em seu lugar na cultura e nos laços sociais, abrigando-as indistintamente sob o adjetivo perverso: em primeiro lugar, desconsidera-se os impactos diversos e singulares que tais práticas podem ter sobre a relação consigo mesmo e com o outro em cada experiência particular e em função do contexto sócio-histórico em que se inserem; em segundo lugar, o que nos parece mais problemático, somos obrigados a localizar em algum outro registro, que não exatamente o das práticas e dos seus efeitos, o ponto em comum em que se possa ancorar tal continuidade.

Nesse momento, entra em cena a ideia de estrutura perversa, a qual, enquanto herdeira involuntária das antigas categorias de sujeito perverso e constituição perversa, ao ser articulada a termos como maldade e crueldade ou se conciliar com um diagnóstico da perversão a partir de determinados efeitos destrutivos ou mesmo mortíferos - e se articular ao que no cotidiano nos referimos, tomando como referência o uso vulgar, pelo termo perversidade - aponta para a produção do que denominamos metapsicologia do mal. Tal metapsicologia se refere ao modo como determinados sujeitos devem ser reconhecidos enquanto sendo em especial 
destinados, como Sade, a pôr em risco aqueles elementos mínimos que, para grande parte dos psicanalistas, tanto definiram as condições de produção do sujeito, quanto permitiriam reconhecer o humano, definindo assim as fronteiras para além da qual já não seria possível sê-lo: "Nem interdito do incesto, nem separação entre o monstruoso e o ilícito, nem delimitação entre loucura e razão, nem divisão anatômica entre homens e mulheres” (ROUDINESCO, 2008, p.53).

\section{PERVERSÃO, LEI E TRANSCENDÊNCIA}

A tomada da perversão como ameaça ao humano através da colocação em risco da ordem simbólica fundada no modelo da filiação e da diferença sexual, aparece também, e desta vez no centro da cena, na obra de Jean-Pierre Lebrun (2008), A perversão comum. Embora o autor faça questão de esclarecer que não se trata da perversão propriamente dita — numa referência direta à noção de estrutura perversa, temos aí esse elemento mínimo que numa espécie de senso comum psicanalítico parece orientar nosso entendimento do que pode ou deve ser qualificado de perverso.

Lebrun parte da constatação de que vivemos uma crise de legitimidade articulada à tentativa de supressão da transcendência e do lugar de exceção, de exterioridade que, segundo ele, tornaria inicialmente possível a linguagem, e em seguida, a própria constituição do sujeito. Partindo da descrição de ordem fenomenológica de certa falência das instituições - "é incontestável que os modos de regulação social não funcionam como antes em nossas sociedades" (LEBRUN, 2008, p.111) — o autor se volta em seguida para os fundamentos psíquicos e simbólicos de tal crise, ou seja, para o que descreve como "uma leitura estrutural dessa mutação do laço social” (idem, p.112).

Tal “crise da legitimidade enquanto tal” (idem, p.220) é marcada pelo cruzamento de fatores subjetivos e sociais: do lado do sujeito, a prevalência do narcisismo e a permanência da onipotência infantil que se materializam na afirmação ou reivindicação do direito individual ao gozo ilimitado; em relação à cultura e à sociedade, a falência ou subversão das hierarquias e das instâncias de autoridade. Duas faces, em verdade, do que Lebrun qualifica de "destituição do transcendental" (idem, p.24).

Tal crise de legitimidade, numa perspectiva psicanalítica deve ainda ser encarada como resultando na constituição de uma comunidade fundada no desmentido e não no recalque. Temos assim uma universalização do mecanismo amiúde vinculado à perversão, o que resulta na produção de neossujeitos, indivíduos que não pagariam o devido preço para completar o processo de subjetivação. O que é desmentido é, fundamentalmente, a "negatividade inerente ao humano" (idem, p.35). 
“Assim, estaríamos de agora em diante numa economia coletiva perversa, outra maneira de dizer que a negatividade não tem mais seu lugar reconhecido como constitutivo da vida coletiva. (...) O que, no entanto, de modo algum implica que os próprios sujeitos tenham, a título individual, se tornado verdadeiramente perversos." (idem, p.39)

Tal negatividade, condição necessária de acesso à linguagem e, portanto, à ordem simbólica que diferencia o homem dos outros animais, se articula ainda à diferença anatômica entre os sexos que, ao que parece, passa a ocupar o lugar da interdição do incesto enquanto elemento decisivo da passagem entre a ordem da natureza e a ordem da cultura.

“Duas faltas vão de certo modo se recobrir. A primeira é um furo cavado no real pelo simbólico, uma perda que instala o nada, via vazio da Coisa, no cerne da linguagem, como a casa vazia necessária para que certos jogos possam continuar. A segunda falta é aquela que está inscrita no campo do Outro, na linguagem, e que pode ser designada como um significante ausente. (...) Logo, uma falta no ser, aquela implicada pela linguagem, precede a falta no ter, no fato de ter ou não ter o falo. O que Freud havia identificado como determinante para a criança, a saber, o confronto com a diferença dos sexos é assim crucial: é dessa maneira que cada ser humano vai apreender a falta no registro do ter." (idem, p.64)

O vazio, o negativo e a castração se configuram então em "invariantes antropológicos", passando a constituir o "núcleo antropológico duro da subjetividade" (idem, p.73) e se estabelecer como condição do humano. A recusa da castração, operada pelo perverso ou pela comunidade perversa, pode então ser pensada como recusa à humanidade. Sendo importante ainda destacar outro risco teórico e ético importante, pois, lembrando Roudinesco — que em seu catálogo histórico abriga na perversão, com certo destaque, aqueles que pretendem desafiar e transgredir em relação à diferença sexual — a colagem entre diferença sexual e Lei faz com que a leitura psicanalítica contemporânea da perversão se revele ainda prisioneira daquilo que afirma sempre pretender libertar-se: o inventário taxionômico dos desvios sexuais que tanto seduziu os positivistas do século XIX e traçou uma espécie de fundamento fenomenológico irredutível do ato perverso. O que se torna evidente pelo lugar estratégico que as subjetividades trans vão ocupar nesse debate ou ainda pelo fato de que ao folhear relatos e descrições de práticas e experiências perversas, a despeito de outras maldades e delitos, sempre se encontre ao menos vestígios de alguma dita deformidade moral da vida sexual ou amorosa. 
Para o autor, capturados pelo desmentido da castração e fixados na recusa à "irredutível necessidade de uma renúncia para instalar a cultura e a lei" (idem, p.250) os neossujeitos colocam-se assim nas bordas da humanidade e transgridem na submissão as hierarquias que sustentam a transcendência necessária. Colocam-se ainda, presos ao gozo, fora do registro do desejo.

"Logo, podemos aqui insistir em dois pontos com frequência deixados na sombra. A saber, que as estruturas sociais sustentam, para cada um, o trabalho do tornar-se sujeito. E que as normas mais fundamentais que a sociedade concreta nos impõe constituem meios - por mais inadequados que sejam — de dar corpo às obrigações da condição humana." (idem, p.92)

Desse modo, o que acaba por se colocar é a afirmação inegociável de um vínculo necessário entre subjetivação, lei simbólica e norma social ou mesmo jurídica, o que faz do adjetivo perverso/a signo, enquanto desafio à lei e transgressão da norma, da impossibilidade de subjetivação.

Não por acaso, o uso técnico, psicanalítico, do termo, com referência direta ao desmentido e à castração, convive com o uso ordinário do termo, próximo ao senso comum, e ao mesmo tempo testemunha da matriz etimológica que remete a desvio e corrupção, por exemplo na afirmação de que em função da crise de legitimidade e da perda de prestígio das hierarquias, o conceito de assédio moral “assim pervertido, agora é efetivamente evocado para designar toda obrigação que o trabalho implique" (idem, p.134, grifo nosso).

O adjetivo perverso assume por essa via um caráter eminentemente moral, o qual — esse nos parece o principal problema — se irradia até a compreensão dita estrutural, psicanalítica, da dita crise de legitimidade, tal como na referência ao trabalho de Pierre Beckouche:

"A democracia pode ser vivida se cada um consegue viver num mundo da negociação onde a regra é mais construída que dada ex ante de maneira rígida. Mas é preciso falar de deriva perversa se o objetivo passar a ser que a jurisprudência substitua a lei, que o direito a substitua a cidadania, o duelo substitua o terceiro, a regulação substitua a regra, o procedimento o processo, o biscate a função, o comum o coletivo, o indiferenciado, o diferenciado, a igualdade a hierarquia." (idem, p.127)

No mesmo movimento, uma série de ideais e valores morais passa a se configurar em elemento estrutural, fundante e diferencial, do humano, fazendo com que a própria ideia de humano se articule, de modo necessário, à ideia de norma. Ou seja, o estatuto do humano passa a ter caráter eminentemente axiológico. 


\section{A TENTAÇÃO DE UMA METAPSICOLOGIA DO MAL}

O que nos parece ser o problema principal, e ponto em comum entre as leituras de Roudinesco e Lebrun, é o modo como a teorização sobre a perversão se transformou de busca da explicação de certas práticas sexuais em tentativa de produção de uma gênese da maldade na qual a ideia de inumanidade ou desumanidade se torna central.

Nesse percurso, perversão se vincula cada vez mais a perversidade, no que se pode descrever como a genealogia de uma leitura psicanalítica da maldade que, ao mesmo tempo, se articula à reivindicação de uma definição psicanalítica do que é o humano. O que nos aproximaria, então, não só de uma metapsicologia do mal, como daquilo que Freud costumava descrever como Weltanschaung.

Ou seja, em função do estabelecimento de uma linha de continuidade entre as mais diversas práticas e experiências, se sobrepõem, em primeiro lugar, os dois eixos de delineamento e interpretação do que seja perverso: o primeiro, que se apoia na tríade identidade, diferença sexual e satisfação da pulsão sexual; o segundo, aquele que se sustenta nas experiências da crueldade e do sofrimento e se vinculam à descarga das pulsões destrutivas.

Por outro lado, a referência a um invariante antropológico e a costura entre a transgressão da norma social e o funcionamento subjetivo baseado no desmentido - aquilo que Lebrun enuncia como descrição do aspecto estrutural da crise de legitimidade que assola o mundo contemporâneo — faz supor possível conferir a tais eixos de delineamento da perversão um substrato metapsicológico preciso.

Como resultante desses dois movimentos o que temos, portanto, é a suposta possibilidade de uma descrição psicanalítica da maldade que costure aspectos semiológicos, marcas identitárias e estrutura subjetiva, ou seja, uma forma de, a partir da psicanálise, localizar no funcionamento de determinados sujeitos, identificáveis a partir dos seus atos, a inteligibilidade da transgressão e, por que não dizer, do crime.

Ou seja, ao tecermos um fio que ligue os dois autores, o que parece se desenhar é a possibilidade de que o estabelecimento de uma descrição do funcionamento subjetivo daqueles que transgridem as normas e desafiam a lei que, com base no pensamento psicanalítico, permita produzir inteligibilidade sobre o Mal, ao mesmo tempo em que circunscreve a maldade a uma forma particular de subjetivação.

É a isso que chamamos metapsicologia do mal, a qual se apoia, por um lado, na continuidade entre diferentes atos e práticas qualificadas, em diferentes contextos sócio-históricos, como perversas, e, por outro lado, no reconhecimento de invariantes antropológicos que permitam definir com clareza os limites entre o humano e o não humano. 
O objeto de tal metapsicologia seria precisamente o Mal que, habitando o sujeito e sendo marca não dos seus atos, mas sim do seu psiquismo, pode manifestar-se das mais variadas formas, cruzando as fronteiras do tempo histórico, das sociedades e das formações culturais.

“Eichmann não era nem sádico, nem psicopata, nem perverso sexual, sem monstruoso, nem acometido por nenhuma patologia visível. O mal estava nele, mas ele não apresentava sinal de qualquer perversão. (...) Era portanto pela manifestação de uma normalidade extrema que Eichamnn encarnava a perversão sob sua forma mais abjeta: gozo do mal, ausência de afeto, gestual automático, lógica implacável, culto do detalhe e do episódio mais insignificante, capacidade inaudita de endossar os crimes mais odiosos teatralizando-os para melhor exibir como o nazismo fizera dele uma criatura monstruosa." (ROUDINESCO, 2008, p.127-128)

Não podendo se ater à semiologia, não apenas pela necessidade de libertar-se da matriz sexológica fornecida pela medicina positivista do século XIX, mas por se ver diante de um catálogo de práticas ditas perversas que não para de crescer e se complexificar, ${ }^{4}$ a psicanálise se dedicou-se à busca de um elemento mínimo que servisse de fundamento metapsicológico da perversão, o que será estabelecido com o mecanismo do desmentido da castração, descrito por Freud no texto sobre o fetichismo, (FREUD, 1927/2006).

Mas a própria ideia de perversão e seu lugar no imaginário ocidental impingiram uma dimensão moral a esse fundamento, fazendo-o vincular-se a signos identificatórios. Desta forma, no primeiro momento, o traço visível da perversão, a partir da clínica dos desvios sexuais, revista pela psicanálise lacaniana, tomou a forma do desafio e da transgressão (DOR, 1991), cabendo aí um grande espaço de discussão na literatura psicanalítica entre a forma e o estatuto do que é desafiado e transgredido: da Lei simbólica, em seu mínimo, na forma da interdição do incesto ou lei da filiação, à norma jurídica, quando o perverso é quase tão somente o criminoso irrecuperável.

Com a tomada do nazismo enquanto objeto, no entanto, ou a consideração de formas instituídas de violência ou mesmo de transgressão e desafio à lei ou aos ideais do Ocidente, tal fundamento cada vez mais se define como maldade, uma pura maldade que, a serviço da lei ou contra ela, colocaria em perigo o próprio estatuto do humano ou mesmo a própria humanidade.

O que nos leva a muitas questões, como o risco da vincular psicanálise e humanismo ou, o que nos parece mais iminente ou mesmo grave, o de procurar

\footnotetext{
${ }^{4}$ Sobre isso, ver: LOVE, Brenda B. (2000) Dictionnaire des fantasmes, perversions et autres pratiques de l'amour. Paris: Blanche.
} 
inscrever na clínica psicanalítica uma forma determinada de subjetivação inscrita na exterioridade do humano, da linguagem e, portanto, da própria clínica, que seria uma espécie de encarnação do Mal, o que nos permitiria paradoxalmente, em última instância, circunscrever este mal e nos protegermos dos seus efeitos. Afinal, apenas as subjetividades pervertidas seriam capazes de permitir que tal maldade se faça ato.

É importante considerar ainda em que medida tal ideia de uma unidade perversa não apenas caminha em direção ao reconhecimento necessário de um Mal em si - que nos provoca a suspeita de que deveria haver também, por outro lado, um Bem absoluto — , mas é ainda tributária de uma visão especificamente moderna de sujeito, na qual este se encontra definido com base nos atributos básicos de "autonomia, imputabilidade, reflexividade, unidade e identidade" (SAFATLE, 2009, p.167). Atributos os quais, precisamente, a invenção freudiana, ajudou a questionar, se inscrevendo entre aqueles que, a partir da modernidade, se perguntaram "quanto devemos pagar para que a unidade, a autonomia, a transparência e a identidade do sujeito possam se impor como realidade?" (idem, p.168).

Por fim, tal metapsicologia do mal se constituiria em um saber apoiado na produção de duas identidades que não apenas seriam inegociáveis e autoexcludentes, mas complementares: uma identidade perversa e uma identidade humana.

\section{NAS FRONTEIRAS DO HUMANO}

Há, no entanto, outra forma de propor o desenvolvimento da aproximação entre as formulações de Roudinesco e Lebrun, apoiada no reconhecimento do caráter necessariamente moral da categoria de perversão, e que nos parece bastante potente para o enfrentamento dos impasses do mundo contemporâneo. Trata-se da referência comum aos limites do humano e a uma potência desumanizante da experiência perversa.

Seja pela via da monstruosidade, pelo destaque a seu caráter infantil ou precário, ou através da formulação de uma subjetivação perversa que produziria neossujeitos ou quase-sujeitos, constrói-se de todo modo uma espécie de núcleo duro da caracterização dos indivíduos perversos que os faz habitar nas bordas da humanidade e operar como ameaça a ela: à humanidade como um todo, ao que há de humano em cada um de nós. Desumanizar torna-se uma espécie de programa comum às múltiplas formas de experiência perversa, nas quais "o desejo é suportado pelo ideal de um objeto perverso" (CHEMANA apud LEBRUN, 2008, p.256), posto que o verdadeiro perverso seria “aquele que fosse levado a dever negar radicalmente a alteridade do outro — seu caráter vivo - , a dever instrumentá-lo” (LEBRUN, 2008, p.256). 
O que não quer dizer, no entanto, que tal potencial de desumanização precisa habitar o sujeito enquanto modo particular de estruturação ou constituição subjetiva e, a partir daí, permitir a delimitação psicanalítica de um domínio da maldade ou o reconhecimento de um povo dos perversos. Ou, indo um pouco mais longe, que não se possa colocar em questão o que configura, a cada momento, o próprio estatuto do humano, bem como as fronteiras e limites do que podemos reconhecer como humanidade.

Assim, o que surge como eixo necessário de investigação é a interrogação sobre o que define o humano e em que medida cabe a psicanálise arbitrar sobre isso, sobre a humanidade e suas fronteiras. Seguir tal direção de pesquisa exige, no entanto, como pressuposto, reconhecer que a perversão não é apenas um diagnóstico que pretende reconhecer uma condição dada pela natureza, inscrita no corpo, na alma ou na mente dos indivíduos, mas sobretudo uma categoria teórica, produzida historicamente e vinculada a certo contexto de articulação entre ciência e moralidade, com a qual pretendemos dar conta não apenas de supostas formas de sofrimento presentes no outro, mas sobretudo elaborar o inquietante estranhamento produzido em nós pelo confronto com certas formas de experiência subjetiva ou de laço social.

Tal linha de investigação nos obriga, ainda, a considerar uma questão preliminar, a qual nos parece não apenas inevitável, mas também inadiável. É com ela que encerramos esta etapa de nossa investigação e concluímos nosso comentário sobre o uso da categoria de perversão na atualidade.

Trata-se de saber se tal perturbação do limite do humano se dá no nível do sujeito ou, o que nos parece mais plausível, no nível da experiência. No primeiro caso, teríamos, como exigência lógica, que pensar em um indivíduo excluído, pelo seu funcionamento psíquico, de qualquer possibilidade identificatória. Pois ainda que tal inumanidade seja "consubstancial à sua humanidade" (ROUDINESCO, 2008, p.45), produz-se aí uma desqualificação radical do sujeito, numa operação muito próxima daquela pela qual o acreditamos responsável: retirar do outro sua humanidade, tornando impossível qualquer identificação com ele ou, em última instância, qualquer laço afetivo. Trata-se aqui de apontar mais uma vez para os riscos de produção de uma identidade perversa, produzindo um campo de exclusão para o qual seriam lançados todos aqueles suspeitos de carregar em si o gozo do mal.

Assim, o estabelecimento de uma identidade perversa pode ser lida como mecanismo paranoico que pretende, a partir da projeção no outro, isolar o mal da nossa experiência e da nossa potencialidade, conferindo-lhe uma identidade negativa que nada seria além da imagem refletida, porém purificada, do nosso próprio ser. O que faria do saber sobre a perversão nosso retrato de Dorian Gray, 
testemunha oculta e material de uma degradação que não podemos suportar em nossos corpos ou atos.

Recebido em 5/12/2012. Aprovado em 22/1/2013.

\section{REFERÊNCIAS}

AULAGNIER-SPAIRANI, Piera. A perversão como estrutura. Revista Latino-americana de psicopatologia fundamental, VI (3) p.43-69.

BARTHES, Roland. (1996) Aula. São Paulo: Cultrix. . (1985) Mitologias. São Paulo: Difel.

BIRMAN, Joel. (2008) Genealogia da transgressão. Cadernos de Psicanálise n.24 (27) p.79-98. Rio de Janeiro: Sociedade de Psicanálise da Cidade do Rio de Janeiro.

CECCARELLI, Paulo. R. (2011) As possíveis leituras da perversão. Estudos de Psicanálise n.36, p.135-148.

DOR, Joel. (1991) Estruturas e clínica psicanalítica. Rio de Janeiro: Taurus/ Timbre.

(1987) Structures et perversion. Paris: Denoël.

FERRAZ, Flávio C. (2000) Perversão. São Paulo: Casa do Psicólogo.

FLORES, Vera M.P. (2010) A perversão e a teoria queer. Tempo psicanalítico n.42 (1) p.131-148.

FREUD, Sigmund. (2010) Obras completas. São Paulo: Cia. das Letras.

(1921) "Psicologia das massas e análise do eu”, v.15, p.13-113.

. (2006) Obras completas. Buenos Aires: Amorrortu.

(1927) "Fetichismo", v.XXI, p.141-152.

GONZAGA JR. \& LUCAS, E. (2008) As relações de trabalho contemporâneas e a perversão. Reverso. v.30, n.56 p.103-110.

GURFINKEL, Décio (2007) Adicções: da perversão da pulsão à patologia dos objetos transicionais. Psichê n.20, p.13-28.

KEHL, Maria Rita. (2008) Publicidade, perversões, fobias. Ide - psicanálise e cultura 31(46), p.27-32.

LANTERI-LAURA, Georges. (1994) Leituras da perversão: história de sua apropriação médica. Rio de Janeiro: Zahar.

LEBRUN, Jean Pierre. (2008) A perversão comum: viver juntos sem o outro. São Paulo: Cia. de Freud.

LOVE, Brenda B. (2000) Dictionnaire des fantasmes, perversions et autres pratiques de l'amour. Paris: Blanche.

MELLO NETO, Gustavo A.R. \& SCHMITT, Lara S. (2011) Perversão e contemporaneidade: um discurso equivocado. Psicologia: Teoria e Prática n.13 (2), p.182-194.

PEIXOTO JR., Carlos Augusto. (1999) Metamorfoses entre o sexual e o social. Rio de Janeiro: Civilização Brasileira. 
ROUDINESCO, Elisabeth. (2008) A parte obscura de nós mesmos. Uma história dos perversos. Rio de Janeiro: Zahar.

SAFATLE, Vladimir. (2009) "Theodor Adorno: a unidade de uma experiência filosófica plural” in ALMEIDA, J. \& BADER, W. (Orgs.) Pensamento alemão no século XX. São Paulo: Cosac Naify.

SOUZA, José C. (1993) A questão da individualidade. São Paulo: Unesp.

Eduardo Leal Cunha

dudalealc@gmail.com 
